\title{
Putting Syntax First: On Convention and Implicature in Imagination and Convention
}

\author{
John Collins \\ School of Philosophy, University of East Anglia
}

\section{Introduction}

As part of a wide-ranging and radical reappraisal of the relation between the linguistic and the extralinguistic in the mind of the competent speaker-hearer, Lepore and Stone (2015) (L\&S, hereafter) offer a characterisation of the so-called 'semantics/pragmatics distinction' under which conversational implicature $(\mathrm{Cl})$ phenomena, traditionally classed as 'pragmatic', are explained in terms of linguistic or grammatical conventions; that is, $\mathrm{Cl}$, at least in some cases, is part of linguistic competence proper, not mere general rationality. L\&S offer many other radical moves against the prevailing consensus. While I applaud their boldness, I shall raise some foundational and more particular concerns for their project, especially as it bears upon what I think is the correct way to proceed in matters linguistic, i.e. syntax should come first.

First, I shall present what I consider to be a highly robust way of drawing the semantics/pragmatics distinction in terms of what is proper to language itself and that which is constituted partly by nonlinguistic cognition. I shall dub my favoured position, the syntax-first conception. The virtue of this position is not so much that it is obviously true or smoothly plots what others have said on the matter, but rather that it is robust, i.e. it provides clear semantic/linguistic invariances across a range of phenomena by fixing on what appears to be an independently established invariant factor in determining what is said, viz. syntax. The cost of beginning with syntax, as it were, is relinquishing a propositional conception of semantics, i.e. semantics, understood as a class of language-specific properties readable from syntax, fixes constraints upon what can be said with an utterance (qua token of a linguistic type), but does not determine a truth-evaluable content as what is said. It will be seen, pace $L \& S$, how a notion of $\mathrm{Cl}$ as essentially a non-linguistic phenomenon follows straightforwardly from this conception, for $\mathrm{Cl}$ rests upon a notion of what is said, which itself is a pragmatic notion.

Secondly, to buttress the above abstractness with a concrete case, I shall critically discuss L\&S's attempted convention-based explanation of speech act $\mathrm{Cls}$. The conclusion will be that such $\mathrm{Cls}$ are syntactically constrained, but remain non-linguistic.

\section{The Syntax-First Conception of the Semantics/Pragmatics Distinction}

Standardly, the semantics/pragmatics distinction is understood as marking dimensions of fixity and freedom that go to determine what can be said with a token of a sentence type. Think of semantics here as a designation of properties of linguistic types that contribute to what is said with a token of the relevant type; being properties of types, they constitute invariances over what is sayable with tokens. Think of pragmatics as designating other ingredient factors that contribute to what is said. These factors will mark variances in interpretation turning on speakers' intentions and other 
prevailing non-linguistic factors that a speaker may intend a hearer to recognise, or simply presuppose. It doesn't follow from this bare distinction, of course, that pragmatics is an unconstrained mess, a bucket for whatever is not linguistic proper. On the contrary, I assume that one can have more or less detailed theories of pragmatic processes, and that such processes may operate under a linguistic licence. The only crucial point for the present discussion is that the upshot of such processes in the form of a truth-evaluable content is not linguistically obligatory. Consider (1):

- (1) Mary shot the elephant in her pyjamas.

(1) is multiply ambiguous depending (inter alia) on the interpretation of her, which may be construed as co-referential with Mary, the elephant, or as deictically valued by way of a contextually salient individual. For a speaker to say something with a token of (1), therefore, involves settling on the value of her, which, sans any extra assumptions, the type (1) does not fix. The assignment of a value (a propositional constituent for a saying) belongs to the realm of pragmatics. The linguistic type alone, however, fixes many features that the pragmatics cannot trump. Her is a singular, feminine nominal, so whatever value it does have must be a female individual. The content of the other lexical items is similarly constrained, even granting some polysemy as regards shoot (the object of shoot can be a target or a projectile). Furthermore, the syntax utterly constrains interpretation: Mary is the shooter (AGENT) and the elephant is the thing shot (PATIENT), not the other way around. The basic thought, therefore, is that linguistic competence alone-a knowledge of English, if you like-will severely constrain what can be said with a token of (1), but not fix any particular truth-evaluable content, for her remains free (albeit constrained) to vary in its contribution to what is said. Assume that a similar partition of the invariant and variant obtains generally. The open question across an indefinite range of cases is what features of interpretation count as invariant (semantic, linguistic proper) and variant (pragmatic, extra-linguistic).

The question just flagged is nigh-on invariably approached by intuitions concerning the range of contents a given linguistic type can support across variations of context. Thus, if the content of a tokened type varies as a function of context of utterance (extra-linguistic factors), then no such content is fixed by linguistic competence alone, which is an invariant condition on what can be said. Crudely speaking, at one end of the spectrum is minimalism, which holds that any token of a wellformed declarative sentence is apt to express a content thanks just to its being of that linguistic type, the exceptions being well-behaved and under a linguistic licence, such as pronouns (and temporalspatial adverbials, etc.) (cp., Borg, 2004; Cappelen and Lepore, 2005). The minimalist need not claim that such a minimal content is normally or even likely to be expressed by a relevant sentence token; her claim is only that the semantic properties of the type suffice to fix such a content, which speakers might eschew for linguistically extraneous reasons. At the other end, is a motley collection of long-held views variously labelled contexualist or pragmatist, unified by the claim that what is said with a linguistic token is underdetermined by linguistic properties (cp. Ziff, 1972; Travis, 1975; Sperber and Wilson, 1986; Recanati, 2004; Pietroski, 2003). An advocate of such a position need not insist that every conceivable sentence underdetermines a content; the minimalist, for instance, might be right about highly regimented discourses. The pragmatist only insists that underdetermination is the typical case and can be seen to hold systematically across a range of diverse constructions. Similarly, the pragmatist should not so much as entertain the idea that pragmatic processes have a free rein in their contribution to the fixing of a content; on the contrary, absolute constraints will issue from whatever the language alone determines. As we just saw with 
(1), syntax and lexical content fix invariant features of what is said, which no pragmatic or extralinguistic process will affect.

As intimated in my introduction, although I think pragmatism is true, the position is not best articulated as a species of mere intuition mongering, where one is offered a ton of examples and told, 'Look! Linguistic properties alone fail to fix a content in this case and that case, for what is said with these tokens differs from what is said with those tokens, so the type-level linguistic properties don't fix what is said'. In the present dialectic, such an exhortation is less than compelling for two basic reasons. Firstly, the minimalist doesn't deny the relevant phenomena, for what is said is characteristically underdetermined by the properties of the linguistic type. The crucial issue is whether there is a type-level content, a question left open by a demonstration that tokens of a given type can support varied contents. Secondly, for all a range of examples show, the linguistic type might well encode the variation of content at the level of the tokens by way of a more articulated covert sentence type as is familiar from linguistic theory. The syntax-first conception is designed to meet these concerns. The conception amounts to a view of the relation between syntax and its interpretation (the syntax/semantics interface), and how this relation enters into fixing a notion of what is said with utterances possessing the syntactic and semantic properties as married at the interface:

I: Syntax: invariant structural conditions on how lexical items can be interpreted in relation to each other. Covert items are happily indulged, but require a syntactic licence, i.e. the item fixes a witnessed invariant interpretation (e.g. PRO, trace/copy, covert functional heads, etc.).1

II: Semantics (= linguistic meaning): whatever syntax (+ licensed lexical content, if any) fixes for the potential content of what a speaker may literally say with a linguistic token; such meaning is characteristically less than truth conditional, because (i) syntax does not fix all truth/reference relevant relations within a projection and (ii) lexical items as projected will classify in terms of their structural role, not any external significance. 2

Putting these claims together, we arrive at four basic hypotheses concerning the semantics/pragmatics interface and the position of the notion of what is said:

(i) Syntax determines linguistic meaning as an invariance of interpretation.

(ii) What is said is not fixed by linguistic meaning, but is constrained by it as a type-level invariance on what can be said with linguistic tokens of the types.

(iii) The extra ingredients of what is said issue from extra-linguistic factors pertaining to context/concepts/speaker intentions.

(iv) Without further notice, Cls will not be part of linguistic meaning, because they are not invariances - trivially, because Cls operate on what is said (literal meaning), which itself is not an invariance. Some implicatures might be included as part of 
linguistic meaning (cp. Chierchia, 2004, on scalar cases), but that will because they have a specific syntactic/lexical licence.

So, pragmatism is true, not so much because of the abundance of content supported by single linguistic types, although this is the case, but because the type-linguistic properties are too sparse to fix a single truth-evaluable content across indefinitely many cases. Furthermore, any would-be covert item whose value is such as to deliver a content for its host is obliged to have a linguistic licence (cp. Collins, 2007). After all, it is not a priori true that language alone delivers content.

L\&S propose a radically distinct conception of the role of grammar in contributing to content. My focus will be on the so-called 'speech act implicature'.

\section{The Speech Act Cl}

Familiarly, (2) gives rise to what is traditionally thought of as a request/imperative $\mathrm{Cl}$ :

(2) Can I have the French toast?

The standard reasoning is as follows. Can expresses a modality of ability or permissibility in the sense that the declarative form $X$ can $F$ expresses the proposition that $X$ is able or allowed to $F$. Thus, when the form is transformed into an interrogative, the reading should be retained, such that Can $X F$ ? is asking after the ability or permissibility of $X$ to $F$. As it is, (2) is not read as a simple polar interrogative to which a waiter, say, may happily respond with 'Yes'; were he to do so, one would consider him to be non-co-operative, or simply obtuse. Rather, $(2)$ is used to make a request/imperative speech act clad in the syntactic garb of an interrogative. The intended speech act is communicated because speaker and hearer assume the same standards of communicative rationality, and the hearer is able to 'calculate' that the speaker is being polite, by making a request in the form of a question: the request is a conversational implicature rationally inferred on the basis of the semantically/grammatically encoded interrogative meaning in order to save the speaker's communicative cooperation. That is the standard story, more or less. In opposition to this picture, L\&S suggest that can is ambiguous/polysemous between an ability and a request reading. Thus, the request option is part of the grammar, not a matter of general rationality realized by way of $\mathrm{Cl}$ reasoning.

(SFC) does not a priori adjudicate on this issue, but instead leaves it open whether this or that aspect of communicated content is linguistic or not, and, indeed, whether a supposed $\mathrm{Cl}$ phenomenon is genuinely extra-linguistic or grammatically encoded. The conception, however, does impose two general conditions that pertain to the case at hand. Firstly, since Cls operate on what is said, which is not typically linguistically encoded, Cls can't be typically grammatical. The point here is that even if one is minded to think that the speech act $\mathrm{Cl}$ is actually grammatical, the case will not generalise in the absence of a general account of how what is said is grammatically fixed. (2) is a convenient example, in this regard, because the force of a sentence is easily marked grammatically, such as by the movement of the auxiliary verb can to sentence-initial position. On the other hand, no linguistic feature will fix the referent of Sally's car, the brick factory, hand axe, and so on indefinitely across the nominal domain. What is sayable by way of these nominals is not fixed as a linguistic matter, but Cl's can still be run on their basis, once what is to be said is settled on a particular occasion. This, however, is a general complaint, which L\&S do not address. In other work, Lepore (Cappelen and Lepore, 2005) does, of course, seek to show that each declarative sentence expresses a minimal 
proposition, but that is not germane. The present point is that $\mathrm{Cl}$ 's operate on what is said, which on no-one's account is exhausted by minimal propositions. If that is so, then Cls just can't be grammatical as things stand. A second consideration imposed by (SFC) is addressed by L\&S.

If some feature of content is to be attributed to language (/grammar), then it must have a linguistic explanation; it can't be parachuted in just for the sake of rendering the relevant feature linguistic.

It is to L\&S's credit that they seek to show that the speech act $\mathrm{Cl}$ is in fact grammatical. If an argument along such lines can be produced in general, then the worry just raised above is made void, for Cls will be shown not to operate on what is said after all, but by way of the relevant grammatical features. I think the prospects for this general strategy are generally gloomy precisely because all of what is said, insofar as a recognized $\mathrm{Cl}$ can run off it, would need to be explained grammatically-an impossible task. The job of explaining Cls on top of that in a similar fashion squares the impossibility, as it were.

Still, all of that said, as mentioned, the request $\mathrm{Cl}$ is a convenient case, precisely because force can be grammatically marked. Even here, however, the reasoning offered by L\&S fails to deliver the intended results.

\subsection{The Role of Please}

Consider the cases in (3):

(3)a Please turn the music down.

b Please can I have the French toast?

c I would like to have the eggs benedict please.

d I'd like a drink please.

e \#I'm thirsty please.

The phenomena here indicate that please associates with a request, where the clause can wear its request character on its sleeve, as with the imperative form in (3a), or be somehow an indirect request as with the respective interrogative and declarative forms in ( $3 b-d)$. The problem case is (3e), where it seems as if the attachment of please is anomalous because I'm thirsty does not support a request/imperative construal. On the face of it, then, please must find a place in the structure that is sensitive to whether the clause it attaches to is a request or not. As L\&S (2014, p. 101) write:

What is please latching on to? It seems like please can accompany requests, as long as they are marked as requests in the usual way, rather than left implicit ... please is diagnostic of a level of linguistic representation in which direct and indirect requests have the same status. This argues that [Cl premises involving requests] are not just associations but are part of the speakers' grammars.

If this reasoning is on the right lines, then we have a nice argument for the grammatical status of requests that cuts across the distinction usually employed in the $\mathrm{Cl}$ analysis; that is, being a request does not merely amount to having an imperative form, and so a non-imperative form employed as a 
request is not necessarily a $\mathrm{Cl}$. If one thought that all non-imperative requests were cases of $\mathrm{Cl}$, then, without further ado, the differential attachment of please would be unexplained. Thus, the ambiguity alternative to $\mathrm{Cl}$ is supported, in that the same term, such as can, may surface in requests and ability questions, the difference marked by the possibility of the attachment of please (inter alia). The reasoning, however, is non-compelling.

Please functions as a marker that the speaker is imposing, and so is asking, in effect, for a favour, following the general maxim: in conversation, Don't Impose! It is equivalent to a if it would please you adjunct, although, as we shall see, it doesn't pattern syntactically as such, for it can append to polar interrogatives. The effect is clear in Spanish, which doesn't have please, but por favor ('Do me a favour'). If that is right, then please should be able to append as an adverbial adjunct to any clause (restrictions will be discussed anon), so long as the context makes it clear that the speaker takes themselves to be imposing. This is borne out. (4), for instance, is fine in a context where answering the question is construed as an imposition. Thus, an interrogative becomes a request with the appendage of please:

(4) Is two plus two four please?

The point generalises to any interrogative. It is not that please attaches to a clause otherwise marked as a request, or is diagnostic of such a clause, but rather that the adjunction renders the clause as a request, because please is indicating that the speaker acknowledges that the provision of an answer is an imposition. The same goes for declaratives, too, so long as the context makes it clear that the speaker is making an imposition upon an interlocutor. Thus, $(3 \mathrm{e})$ can be rendered fine:

(5) A: What would you like? Food or drink?

B: I'm thirsty please

Here, in the context, the speaker's being thirsty amounts to an imposition, given the understanding that the speaker's thirst is to be quenched by the hearer. Of course, such a story grades off in plausibility where the declarative invites no response that is an imposition. For instance, Paris is the capital of France please makes little sense off the bat, because no action is invited that is an imposition. One could make sense of the utterance, however, as an answer to a choice, much like in (5).

In general, then, far from please suggesting that the $\mathrm{Cl}$ account of speech acts is in error, its free distribution under syntactic constraints supports the $\mathrm{Cl}$ account, for there appears to be no level of analysis whereby interrogatives or declaratives are constituted as requests, or at least no such level revealed by the distribution of please. Thus, if one wants to form a request sans an imperative form, grammar alone will not do the job.

Purely syntactic considerations point in the same direction. Thus, please can appear anywhere outside of the VP and TP domains: 
(6) a Please turn the music down/Turn the music down please.

b [FOR Please [FOR can [FIN you] [TP $<$ you $><$ can $>$ turn the music down]]]3

c [FOR [FOR Can [FIN you] please [TP $<$ you $><$ can $>$ turn the music down]]]

d Can you $[$ TP $<$ you $><$ can $>$ turn the music down] please?

$\mathrm{e}^{*}$ Can you turn please the music down?

$f *$ Can please you turn the music down?

$\mathrm{g}$ *Turn please the music down!

The phenomena here indicate that please serves as an adjunct of force rather than an item selected, argument-like, given a grammatical organisation that encodes requests. Thus, (6b-d) witness that please can occur as an adjunct associated with FORCE outside of TP. Please, in other words, modifies the force of the clause, but, qua adjunct, leaves the force intact, rather than changes it to some other kind of request/imperative force. In $(6 \mathrm{e}-\mathrm{g})$, it is witnessed that please can only adjoin in the FORCE domain. The same considerations, of course, apply to declaratives in that please can only occur initially or finally, for there is no movement to FORCE in such cases. There are some complications, however.

Please is happy with imperatives + subject, but only after the subject:

(7) a *Please everyone wait.

b Everyone please wait.

It is not clear to me what these phenomena indicate. They don't so much refute the hypothesis made above as suggest that the marking of force in these cases is unclear. For (7b) is predicted, if we take the subject to move from SPEC-TP. It would then be as if (7b) is derived from (7a), but the purpose of such putative movement remains unclear.

There is also a semantic effect. Please is OK as adjoined to a complement (non-finite or subjunctive) so long as the matrix verb is a speech-act verb:

(8)a I asked/requested/implored him to please turn the music down.

b I asked/requested/implored that he please turn the music down.

c *I imagined/expected him to please turn the music down.

$d^{*}$ I prefer that he please turn the music down.

It will be noted that please cannot occur outside of the embedded clause in (8a-b), either sentence initial or final positions, and please in such positions does not rescue $(8 c-d)$. It appears, therefore, as 
if please can be reported as part of the content of the speech act, if the act is of the right imperative/interrogative sort. Thus, the cases in (9) are not perfect:

(9) a ? said that he must please turn the music down.

$\mathrm{c}$ ?! wondered whether he would please turn the music down

I think the considerations so far marshalled clearly indicate that please offers no support for the thought that can is ambiguous between an ability and a request construal, for there is no grammatical request level at which please selectively occurs. As just witnessed with (8-9), please is clearly semantically related to requests, and this has its grammatical signature, but none of this even intimates any grammatical level of requests. L\&S, however, have other arguments.

\subsection{The Role of Able}

Consider:

(10) Am I able to have the French toast?

(10) is certainly an unhappy formulation of a request, and is awkward with please. Thus, L\&S reason:

English speakers somehow know that [Can I have the French toast?], rather than [(10)], is the ordinary formulation of an indirect request-and this factors strongly into how we produce and interpret utterances involving the terms ... [T] his suggests that [Cl request premises] are not associations, but are part of speakers knowledge of language (Lepore and Stone, 2014, p. 102).

The thought is that if can univocally carries the standing able meaning, and no request meaning, and so can only be recruited for a request via $\mathrm{Cl}$, then, ceteris paribus, (10) should be able to serve as a request, but it can't, and is especially bad with please, or so goes the intuition of L\&S. Thus, the use of can as a request signals that the auxiliary carries the request meaning rather than the request being a $\mathrm{Cl}$ association. There are two problems with this line of reasoning.

Firstly, the use of (10) as a request (with or without please) is at best stilted, rather than ungrammatical in any sense, and please, if adjoined, must be in a FORCE position. Secondly and more substantively, whatever oddity there is to (10) is independently explicable. If, as we are assuming, please registers the speaker's recognition of imposition, then the oddity of (10) + please follows from the imposition being explicitly cancelled with the semantically heavy able in distinction to the light auxiliary can. That is, there is no presumption on the speaker's part that the interlocutor can satisfy the intended request. The cases in (11) are equally stilted, although not entirely out, for the same reason, it appears:

(11) a Would it be possible to have the French toast please?

b Do you still have French toast please? 


\subsection{Ambiguity, the Very Idea}

L\&S's idea, in general, is that speech act $\mathrm{Cl}$ is really a case of ambiguity. L\&S do not attempt to unpack this claim, but appear to assume that the work the claim may do offers enough justification for the hypothesis. There are, however, numerous tests for ambiguity that may be deployed, although it must be stressed that the tests are defeasible, especially given acceptable zeugmaticity. I take it that L\&S win, as it were, if can comes out polysemous, even if not precisely ambiguous. Similarly, it is difficult to test for ambiguity in the case of auxiliaries, rather than nominals or lexical verbs, say. Still, consider the following case. Let's assume that (12a) has a default generic able reading, and, obviously enough, $(12 \mathrm{~b})$ has a request reading:

(12) a Can you love without selfishness

b Can you leave please

If that is right, then their conjunctions should be unacceptable:

(13) a Can you leave please and love without selfishness?

b Can you love without selfishness and leave please?

To the contrary, both have a request construal as opposed to being ambiguous, unacceptable, or having a uniform able interpretation. Of course, if conjuncts, elliptical or otherwise, must have a joint construal, then this is predicted, but terms can't have a joint construal, if what is conjoined have respectively distinct resolutions, as we are assuming obtains between (12a) and (12b). The single construal, however, is perfectly in line with please adjoining as a FORCE adjunct that scopes over the conjunctions. The test works equally well without please, but its inclusion does make vivid that there is no anomalous effect from the putative ambiguity of can, and that the resolution always follows the request construal.

\section{Conclusion}

L\&S are right to claim that communication involves everything and the kitchen sink, and so, a model comprising just 'grammar' and rationality is too simple. However, we may part company with what L\&S model as part of the grammar. Further, my austere (SFC) alternative recognises the complexity while factoring what is said to be part of that complexity, a fortiori $\mathrm{Cl}$ phenomena typically work on the basis of what is said in the absence of any grammatical account of the effect. Grammar constrains rather than fixes what we can say with language. For example, syntax constrains the position of please as an explicit marker of requests, but doesn't support a level of representation where requests are marked as such. Or so it seems.

1

My claim is that syntax provides at least such conditions on interpretation; it also provides much else, of course, such as the organisation of morphology and phonology at various levels. 
On the first point, syntax will, for example, leave unspecified many relations of attribution that give rise to familiar cases of polysemy and ambiguity (red leaves, Mary's car, etc.). On the second point, lexical items will carry a great deal of information to which the linguistic system is insensitive.

3

The angled brackets mark positions unpronounced in the structure but occupied by copies of items that are copied or move higher up the structure to the left. Following 'cartographic' analyses, I assume that the clause has a left periphery with functional projections marking finiteness (FIN) and Force (FOR), and other features too, which are presently irrelevant, with copied items occurring in the SPECs of the projections. To take please to be an adjunct of FOR, is to position it so that it extends the FOR projection. There is precious little syntactic discussion of please, so the following remarks are my own, but for general discussion of this syntactic framework, see Rizzi, 1997, and Haegman, 2012. 